\title{
Intestinal obstruction secondary to a congenital pre-iliac hernia
}

\author{
A.K. Siriwardena
}

Department of Surgery, Bangour General Hospital, Broxbourn, West Lothian EH52 6LR. UK.

\begin{abstract}
Summary: A previously undescribed type of congenital abdominal wall hernia is described. Presentation was with the symptoms and signs of subacute large bowel obstruction. The diagnosis was suggested by barium enema and confirmed at laparotomy.
\end{abstract}

\section{Introduction}

An elderly man presented with subacute large bowel obstruction which was found to be due to incarceration of colon in a hernial sac in the anterior abdominal wall. On reviewing the classification of rarer abdominal herniae, it is suggested that the patient had a previously undescribed congenital hernia.

\section{Case report}

An 81 year old Caucasian male presented with a 2 month history of left lower abdominal pain. This was of gradual onset, localized to the left iliac fossa and associated with gradually increasing constipation. His bowel habit had changed from once a day to every $2-3$ days, the stools were small and hard, and there was no blood or slime. Admission was precipitated by a 12 hour episode of colicky pain in the left iliac fossa.

On examination he was afebrile, his pulse was $84 /$ minute and he was not shocked. His abdomen was soft and there was a $6 \times 8 \mathrm{~cm}$ mass in the left iliac fossa. This was slightly tender, non-pulsatile and deep to skin but appeared to be involving the muscle layer of the anterior abdominal wall. Bowel sounds were normal and rectal examination revealed hard faeces. An erect chest X-ray was normal. A plain abdominal $\mathrm{X}$-ray was also thought to be normal, although subsequently the films were seen by a consultant radiologist who suggested the diagnosis of an anterior abdominal wall hernia on the grounds of gas being visible external to the iliac crest.

A differential diagnosis of subacute large bowel obstruction secondary to either diverticular disease or neoplasm was made and initial treatment was by

Correspondence: A.K. Siriwardena, F.R.C.S.Ed., F.R.C.S. Wards 13/14, Royal Infirmary of Edinburgh, Lauriston Place, Edinburgh EH3 9YW, UK.

Accepted: 17 August 1988 observation, oral fluids and oral cotrimoxazole. Sig moidoscopy carried out on the day of admissiop revealed normal mucosa to $15 \mathrm{~cm}$.

On this regime his pain settled and his bowel $\overrightarrow{\mathbb{S}}$ moved, but the mass persisted. An urgent bariung enema showed a smooth narrowing in the distal descending colon, with large bowel appearing to enter a hernial sac (Figure 1). The examination had to be terminated as the patient experienced severe lowe abdominal pain. It was decided to proceed t $\sigma$ laparotomy. Under anaesthetic the mass was eaฐlly palpable. On opening the peritoneal cavity the petiog colon was seen to disappear through a $4 \times 4$ 迎 opening, $5 \mathrm{~cm}$ lateral to the rectus sheath and aböu娄 $4 \mathrm{~cm}$ proximal to the mid point of the inguinas ligament (Figure 2). The sac extended out over the anterior superior iliac spine and over the lateral part of the inguinal ligament. The neck of the sac was clearl definable and it was seen to be constricting the large bowel. The contents of the sac were reduced and the defect repaired with mattress sutures of polydiox anone. Post-operative recovery was unremarkable and there was no evidence of recurrence at review three months later.

\section{Discussion}

The 'rarer' abdominal herniae account for $1.5 \%$ of the total. ${ }^{1}$ Before presenting a hernia as being previous underscribed, it is important to conside carefully whether or not it belongs to one of theso groups of rare herniae already documented. The hernia presented in this case did not involve the inguinal canal or deep inguinal ring and therefore could not have been an inguinal hernia. A Spigeliari hernia passes through a defect in the linea semilun aris. ${ }^{2}$ The hernia in the case presented arose from $\$$ defect considerably lateral to the rectus sheath and 


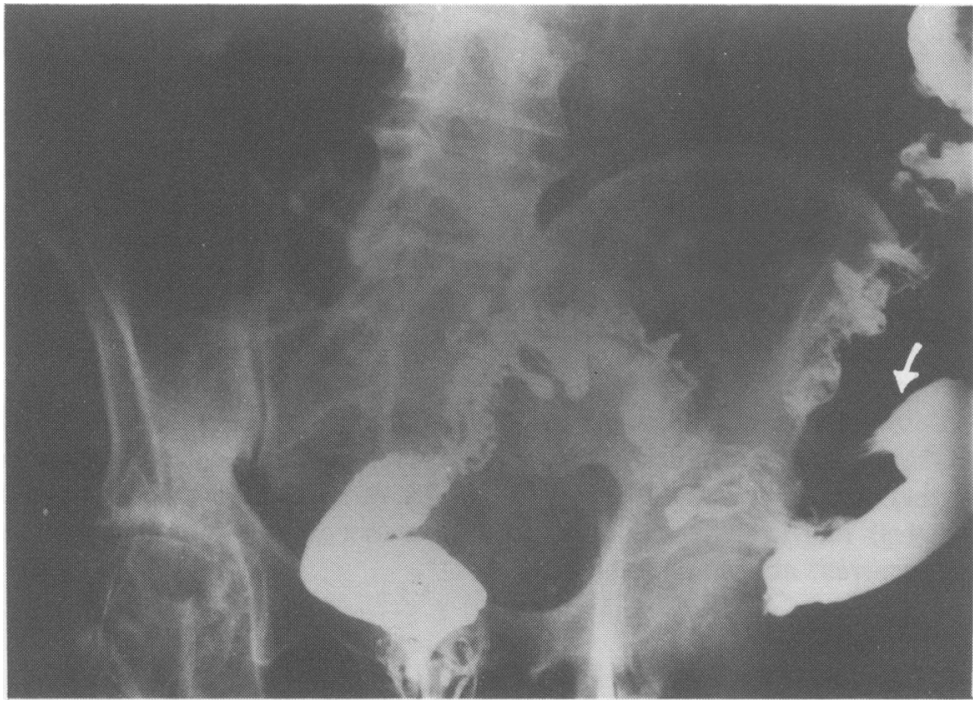

Figure 1 Barium enema. Contrast is seen outlining the hernial sac (arrowed).

thus by definition could not have been a Spigelian hernia. A lumbar hernia arises from below the 12th rib and above the iliac crest posteriorly. This excludes the hernia presented in this case as the primary defect was in the anterior abdominal wall. Could the hernia have been of the acquired type? An absolute answer to this questicn is not possible, but it must be remembered

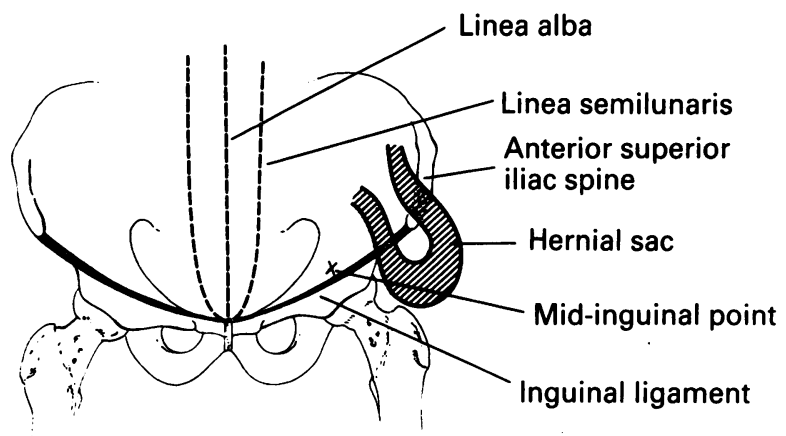

Figure 2 Anterior view of pelvis showing position of hernial sac.

\section{References}

1. Harding Rains, A.J. \& Ritchie, H.D. (ed.) - Bailey and Loves A Short Practice of Surgery. 19th Edition, H.K. Lewis, London, 1984, p.1076.

2. Maingot, R. Abdominal Operations. 7th Edition, Appleton Century Croft, Norwalk, USA, 1980, vol. II, pp. 1656-1661. that there had been no previous surgery in this area, and that a well defined neck and sac were found. This suggests that the hernia was in fact congenital in nature. A further point is that it is unusual for a hernia to lie outside the iliac crest. Although herniae haves been described as reaching this position by passing through a defect in the iliac crest after the taking of a full thickness bone graft, ${ }^{3}$ there is no published description of a hernia reaching this position in the absence of previous surgery.

It is well recognized that inter-parietal herniae may contain bowel and present with the symptoms and signs of intestinal obstruction, but a search of previous publications has failed to show any description of a congenital inter-parietal hernia crossing the iliac crest to lie in a pre-iliac position.

\section{Acknowledgements}

I thank Mr A.A. Gunn, consultant surgeon, Bangour General Hospital, for permission to report this case. I am grateful to the Royal College of Surgeons of Edinburgh for carrying out a detailed computerized search of the literature.

3. Kinninmonth, A.W.G. \& Patel, P. Herniation through a donor site for iliac bone graft. J R Coll Surg Edinb 1987, 32, 246. 